\title{
Acute small bowel obstruction: a rare initial presentation for the metastasis of the large-cell carcinoma of the lung
}

Yongmao Song ${ }^{2}$, Modan $\mathrm{Li}^{1}$, Jianzhen Shan ${ }^{1}$, Xiaoxian Ye ${ }^{1}$, Shangyi Tang ${ }^{1}$, Xuefeng Fang ${ }^{1}$, Kefeng Ding ${ }^{2}$ and Ying Yuan ${ }^{1 *}$

\begin{abstract}
We present one case with symptom of paroxysmal abdominal pain for over 20 days. Abdominal computerized tomography (CT) scan revealed intestinal obstruction and a mass of $6.0 \mathrm{~cm} \times 6.0 \mathrm{~cm}$ in size located at the left adrenal. Chest CT scan showed a lobulated mass of $2.7 \mathrm{~cm} \times 2.7 \mathrm{~cm}$ in size at the upper left lung. Core needle biopsy of the lung mass confirmed the diagnosis of large cell carcinoma. The patient underwent an emergency abdominal laparotomy and received a chemotherapy regimen that consisted of pemetrexed and cisplatin postoperatively. In addition, we made a review of the literature of the occurrence, diagnosis and outcome of this manifestation.
\end{abstract}

Keywords: lung cancer, metastasis, obstruction, gastrointestine

\section{Background}

Primary lung cancer is one of the leading causes of death in China. Gastrointestinal (GI) metastasis as the initial presentation of primary lung cancer is relatively rare in the clinic. Acute GI symptoms such as obstruction, perforation or bleeding could be the results of small bowel involvement. We report one case of metastatic large cell carcinoma of the lung with the primary presentation of acute small bowel obstruction. The current management plan, as well as prognosis of this patient is discussed. GI metastasis of lung cancer occurs late in the course of the disease and is associated with serious clinical complications and outcomes. Also, we made a review of the literature relevant to the occurrence, diagnosis and outcome of GI metastases of lung cancer.

\section{Case presentation}

A 58-year-old male patient with a history of meningioma surgery was admitted to the Emergency Department with a chief complaint of episodes of paroxysmal abdominal pain. The pain started 20 days previously that was

\footnotetext{
* Correspondence: yuanying1999@zju.edu.cn

'Department of Medical Oncology, the $2^{\text {nd }}$ Hospital of Zhejiang University

College of Medicine, Hangzhou, Zhejiang, 310009, P.R. China

Full list of author information is available at the end of the article
}

aggravated for the last 2 days. Slight tenderness over the left epigastric region and active bowel sounds were observed during physical examination. Plain abdominal X-ray showed dilatation of small bowel with multiple gasfluid levels. The abdominal computerized tomography (CT) (Figure 1) scan revealed intestinal obstruction and a mass of $6.0 \mathrm{~cm} \times 6.0 \mathrm{~cm}$ in size which showed enhancement in contrast-enhanced CT near the left adrenal gland. The chest CT (Figure 2) scan showed a $2.7 \mathrm{~cm} \times 2.7 \mathrm{~cm}$ lobulated mass at the upper left lung with localized pneumonia changes. Brain MRI suggested no evidence of cerebral or cerebellar metastasis. A CT-guided core needle biopsy of the lung mass confirmed the diagnosis of large cell carcinoma of the lung(Figure 3).

Due to the life-threatening nature of complete obstruction, the patient underwent an emergency abdominal laparotomy. Exploration of the abdominal cavity revealed a mass of $12.0 \mathrm{~cm} \times 10.0 \mathrm{~cm}$ in size in the jejunum which had already invaded the bladder. The abdominal computerized tomography scan revealed metastatic tumor mass of jejunum (Figure 4). The mass, the invaded jejunum and part of the bladder was resected. Another hard and fixed mass of $6.0 \mathrm{~cm} \times 6.0 \mathrm{~cm}$ in size near the left adrenal gland was also identified and it was not removed during the procedure due to its invasion to the surrounding of great 


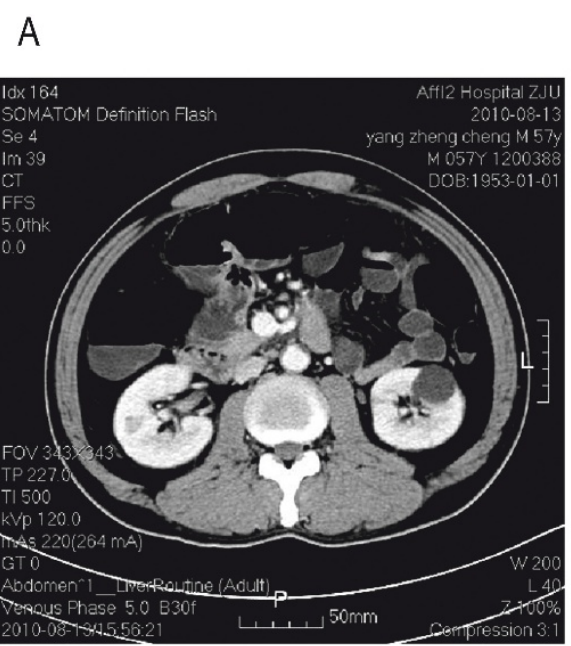

\section{B}

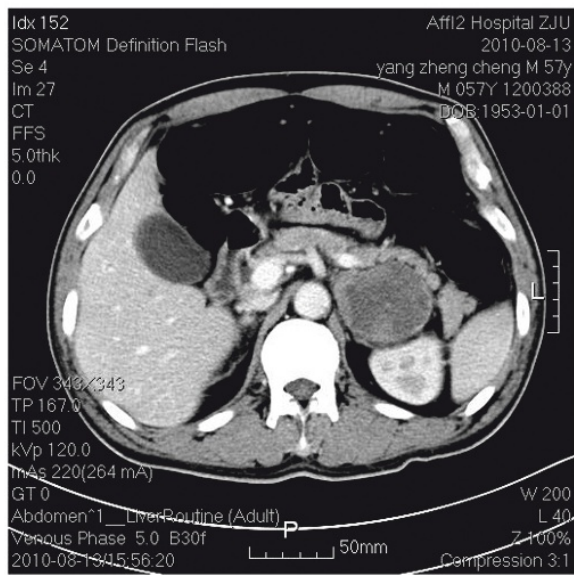

Figure 1 The abdominal computerized tomography scan revealed intestinal obstruction (a) and a mass measuring of $6.0 \mathrm{~cm} \times 6.0 \mathrm{~cm}$ in size which showed enhancement in intensified tomography near the left adrenal gland (b).

vessels. Post-operative pathological analysis of the surgical specimen showed the presence of poorly differentiated carcinoma with rhabdoid differentiation (Figure 5). Immunohistochemical (IHC) staining revealed that the tumor cells were positive for CK7, vimentin, and partially positive for CA153 receptors. Combining with the results of the lung biopsy, we concluded that the jejunal mass was a metastasis from the primary large cell carcinoma of lung.

Postoperatively, the patient complained severe continuous upper left abdominal pain which intensified

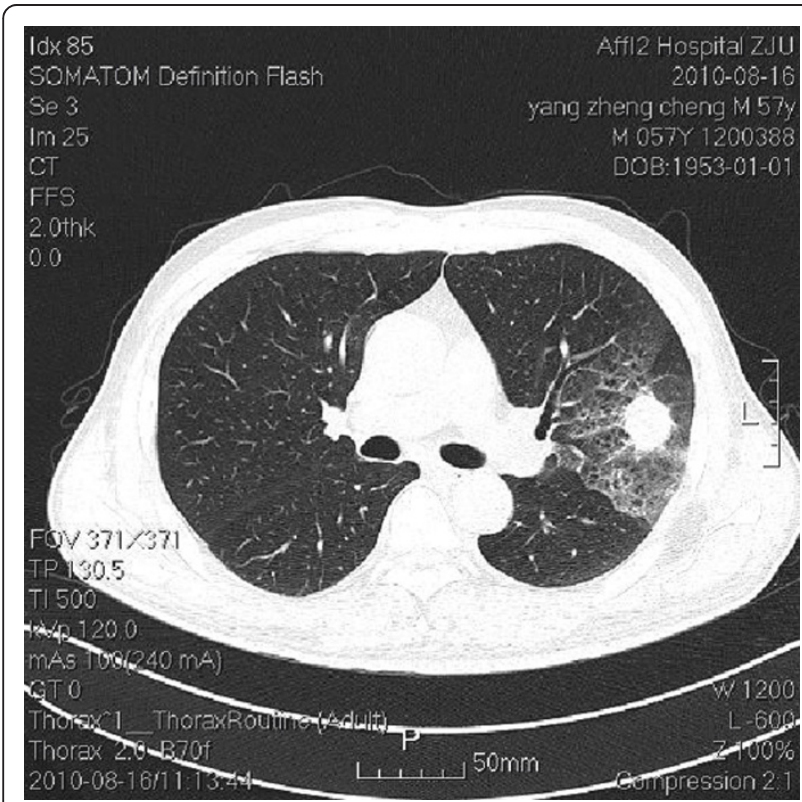

Figure 2 The chest computerized tomography scan showed a $2.7 \mathrm{~cm} \times 2.7 \mathrm{~cm}$ lobulated mass at the upper left lung with localized pneumonia changes. progressively. Additional CT scan revealed that the mass near the left adrenal gland had swollen to $8.8 \mathrm{~cm} \times 8.3$ $\mathrm{cm}$ in size, while the upper left lung mass had increased to $4.5 \mathrm{~cm} \times 4.0 \mathrm{~cm}$ in size, and localized pneumonia, atelectasis and pleural effusion of left thoracic cavity had also developed. The patient was diagnosed with stage IV large cell lung cancer with jejunum and left adrenal gland metastasis. The chemotherapy regimen consisted of pemetrexed $500 \mathrm{mg} / \mathrm{m}^{2}$ at day 1 and cisplatin $25 \mathrm{mg} /$ $\mathrm{m}^{2}$ on day 1 to day 3 . However, the abdominal pain was not relieved with this treatment. Two weeks after the first cycle of chemotherapy, the patient suddenly presented with abnormal activities of the right limbs, with a positive result in the finger-to-nose test. New brain MRI scan revealed multiple metastatic lesions with prominent surrounding edema in various cerebral and cerebellar regions. The patient suffered an epileptic seizure and died three days later.

\section{Discussion}

The most frequently involved metastatic organs of lung cancer are bones, liver, brain and adrenals, while metastases to the gastrointestinal system is relatively rare with a frequency ranging from $0.2 \%$ to $1.7 \%$ in several studies [1-3]. However, autopsy data have suggested a much higher frequency of GI metastases of lung cancer than clinically reported cases and there is a prevalence of $4.7 \%$ to $14 \%[4,5]$. Small bowel is the most commonly reported GI metastatic site of lung cancer $[5,6]$. Clinically significant metastases to the small bowel are rare and occur only in the advanced stage of lung cancer. Most patients with small bowel metastases have no specific symptoms such as anorexia, abdominal pain, distention and diarrhea. With the progression of disease, 


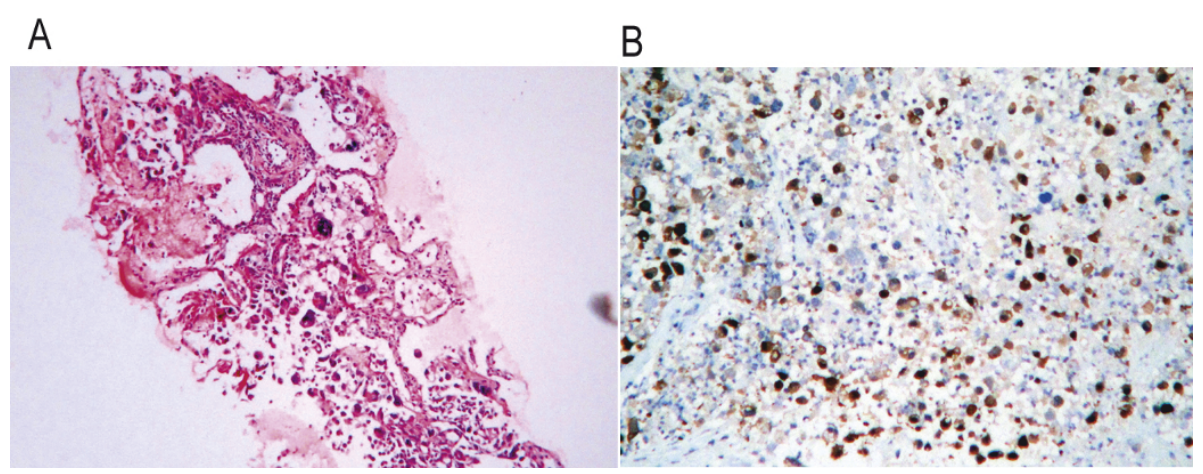

Figure 3 Microscopic images of lung biopsy (a) hematoxylin-eosin staining $\times 100$, showing large, undifferentiated tumor cells with rhabdoid variant; (b) immunoperoxidase $\times 400$ showing CK7 immunoreactivity of cancer cells.

life threatening symptoms do present, such as small bowel obstruction, perforation or even bleeding[7-10]. Hillenbrand reviewed the literature from 1967 to 2003 and found 58 documented cases with metastasis to the small bowel of primary lung cancer. Over $80 \%$ of the cases with small bowel metastases were male, with ages ranging from 36 to 78 years old and metastases presented as perforation (59\%), obstruction (29\%) and hemorrhage (10\%) [11]. In addition, McNeill et al. [6] reported that small bowel metastases were always associated with other metastatic sites (with an average of 4.8 sites), thus suggesting a late stage of the lung cancer. These patients often had a poor prognosis with a lifeexpectancy less than 16 weeks.

Yang et al. [1] reported in their study that squamous cell carcinoma is the most common cell type of lung cancer which develop GI metastases $[2,4,12]$. But other studies showed that poorly differentiated adenocarcinoma and large cell carcinoma of the lung have higher incidence of GI metastases. McNeill et al. [6] reported that 12 of $31(39.0 \%)$ patients with large cell carcinoma had small bowel metastases. Yoshimoto et al. [4] evaluated
470 cases of GI metastases from primary lung cancer over 33 years and their data showed that $30 \%$ of cases were large cell carcinoma. Patients with large cell carcinoma had a significantly higher rate of GI metastases $(\mathrm{P}=0.004$, odds ratio 3.524) compared with patients with non-large cell carcinoma. Because of the difficulty in early detection of GI diseases, the diagnosis of small bowel metastases was often delayed before it presented with life-threatening complications, which frequently required emergency surgeries $[1,13]$. Kim evaluated the CT scan findings in 28 patients with gastrointestinal metastasis from lung cancer and found $5 / 26$ patients had two lesions and 21 patients had only one lesion. The shape of GI lesion varied on CT scans, presenting as wall thickening in 14 cases, an intraluminal polypoid mass in 14 cases, and an exophytic mass in the other three cases [14]. PET is more accurate than CT or other conventional imaging methods for the diagnosis of metastatic malignant sites. However, the role of PET in the diagnosis of lung cancer GI metastasis is still controversial because of the lack of enough clinical cases. Small bowel metastases from primary lung cancer were usually
A

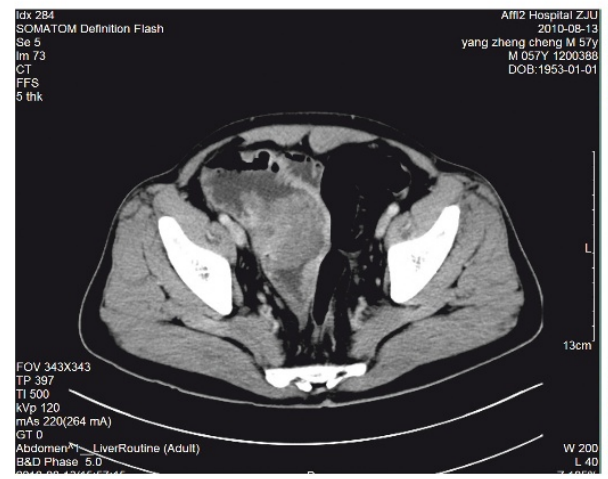

B

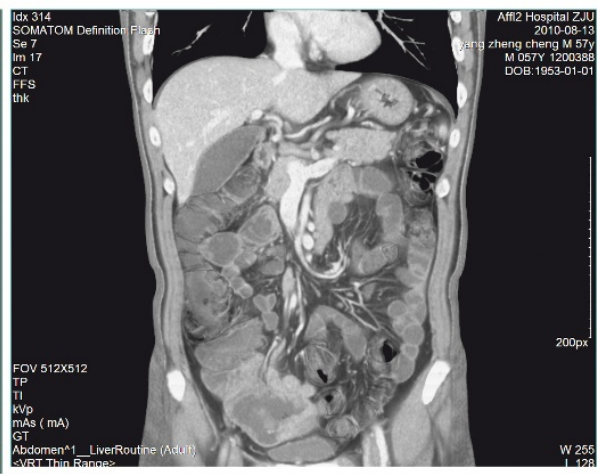

Figure 4 The abdominal computerized tomography scan revealed metastatic tumor mass of jejunum (a and b). 


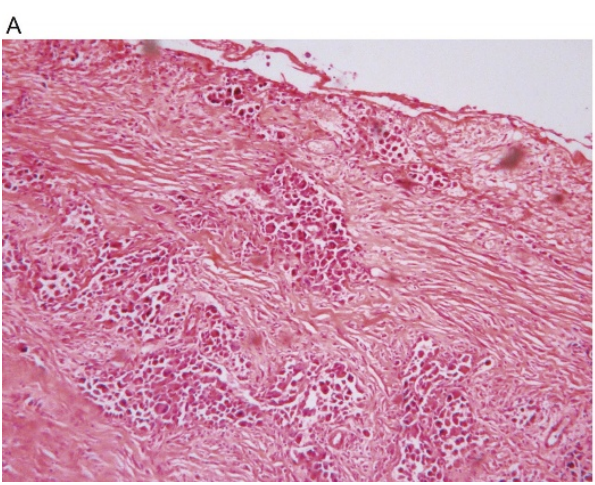

\section{B}

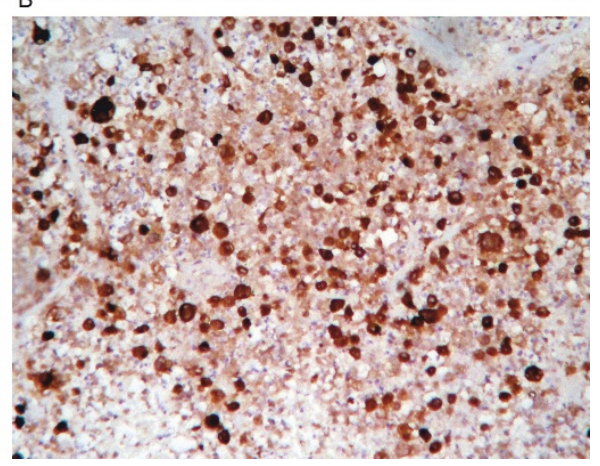

Figure 5 Microscopic images of jejunum resection (a) hematoxylin-eosin staining, $\times 100$ showing groups of large anaplastic tumor cells invading the lamina serosa; (b) immunoperoxidase $\times 400$ showing CK7 cytoplasmic positivity on a jejunum resection tissue.

confirmed by pathological analysis, with the help of immunohistochemical staining of TTF-1, CDX2, CK7 and CK20, to differentiate the primary small bowel tumor from metastases of lung cancer [2].

So far, surgical resection is the mainstay treatment for small bowel metastases from large cell carcinoma of the lung. Individualized treatment may also be helpful. Advances in chemotherapy and supportive care may lead to the improvement of the survival rate for these lung cancer patients. According to the report from a phase III study (JMDB trial), overall survival was statistically higher in patients with large cell carcinoma histology who received treatment of cisplatin plus pemetrexed versus cisplatin plus gemcitabine, the latter being the standard first-line regimen of non-small cell lung cancer; $\mathrm{n}=153$; 10.4 months v 6.7 months, respectively [15].

In our case, small bowel obstruction was the initial clinical symptom for this male patient. Primary lung large cell carcinoma was confirmed by a pathologist and at the same time small bowel and left adrenal metastases were suggested by CT scan (stage IV). Unfortunately the patient did not benefit from an emergency operation and chemotherapy. Multiple brain metastases soon developed and the patient died 64 days after the diagnosis. The histological type of large cell carcinoma of the lung, metastases in multiple sites, heavy tumor load and surgical stroke might be the reasons of the poor prognosis. During the clinical course, physicians should be aware of gastrointestinal tract metastases if the patient with lung cancer presents with gastrointestinal tract symptoms. Progression of examinations for screening small bowel diseases will be helpful for doctors to diagnose more cases of small bowel metastases from lung cancer in the future. Earlier resection of the gastrointestinal metastases to alleviate the symptoms and decrease tumor load may be beneficial to the patients and achieve a better prognosis [11,16-18].

\section{Conclusion}

In conclusion, small bowel metastases from lung cancer are not uncommon and occur only in the advanced stage of lung cancer, particularly if patients have the histological type of large cell lung carcinoma. Physicians should keep in mind that the incidence of small bowel metastases as a site of lung cancer spread is increasing as patients with lung cancer now live longer due to improved treatment.

\section{Consent}

Written informed consent was obtained from the patient for publication of this case report and accompanying images. A copy of the written consent is available for review by the Editor-in-Chief of this journal.

\section{Abbreviations \\ $\mathrm{CT}$ : computerized tomography; Gl: gastrointestinal; IHC: immunohistochemical.}

\section{Author details}

'Department of Medical Oncology, the $2^{\text {nd }}$ Hospital of Zhejiang University College of Medicine, Hangzhou, Zhejiang, 310009, P.R. China. ${ }^{2}$ Department of Surgical Oncology, the $2^{\text {nd }}$ Hospital of Zhejiang University College of Medicine, Hangzhou, Zhejiang, 310009, P.R. China.

\section{Authors' contributions}

YM S wrote the manuscript. YM S, KF D and SY T performed surgery. Y Y carried out the pathological examination. $Y Y$ and $X F F$ was involved in the final editing. Y Y, MD L, XX Y, JZ S carried out chemothreapy. All authors approved the final manuscript

\section{Competing interests}

The authors declare that they have no competing interests.

Received: 1 August 2011 Accepted: 29 January 2012 Published: 29 January 2012

\section{References}

1. Huang MS: Gastro-intestinal metastasis of primary lung carcinoma: clinical presentations and outcome. Lung Cancer 2006, 54(3):319-23.

2. Rossi G, Marchioni A, Romagnani E, Bertolini F, Longo L, Cavazza A, Barbieri F: Primary lung cancer presenting with gastrointestinal tract 
involvement: clinicopathologic and immunohistochemical features in a series of 18 consecutive cases. J Thorac Oncol 2007, 2(2):115-20.

3. Lo CK, Kao SS, Tai DKC: Gastrointestinal metastasis from primary lung cancer. Surgical Practice 2009, 13(3):73-76.

4. Yoshimoto A, Kasahara K, Kawashima A: Gastrointestinal metastases from primary lung cancer. Eur J Cancer 2006, 42(18):3157-60.

5. Antler AS, Ough Y, Pitchumoni CS, Bertolini F, Longo L, Cavazza A, Barbieri F: Gastrointestinal metastases from malignant tumors of the lung. Cancer 1982, 49(1):170-2.

6. McNeill PM, Wagman LD, Neifeld JP: Small bowel metastases from primary carcinoma of the lung. Cancer 1987, 59(8):1486-9.

7. Pollheimer MJ, Eberl T, Baumgartner K, Pollheimer VS, Tschmelitsch J, Lackner $\mathrm{H}$, Langner $\mathrm{C}$ : lleocecal intussusception caused by lung cancer metastasis. Wien Klin Wochenschr 2009, 121(11-12):413-6.

8. Stenbygaard LE, Sørensen JB, Larsen H, Dombernowsky P: Metastatic pattern in non-resectable non-small cell lung cancer. Acta Oncol 1999, 38(8):993-8.

9. Berger A, Cellier C, Daniel C, Kron C, Riquet M, Barbier JP, Cugnenc PH, Landi B: Small bowel metastases from primary carcinoma of the lung: clinical findings and outcome. Am J Gastroenterol 1999, 94(7):1884-7.

10. Yildirim M, Tasli F, Bayam ME, Postaci H: A rare cause of small bowel transection: metastatic lung cancer. Med Princ Pract 2010, 19(3):232-4.

11. Hillenbrand A, Sträter J, Henne-Bruns D: Frequency, symptoms and outcome of intestinal metastases of bronchopulmonary cancer. Case report and review of the literature. Int Semin Surg Oncol 2005, 2:13.

12. Tomas D, Ledinsky M, Belicza M, Kruslin B: Multiple metastases to the small bowel from large cell bronchial carcinomas. World I Gastroenterol 2005, 11(9):1399-402.

13. Nagashima Y, Okamoto H, Narita Y, Hida N, Naoki K, Kunikane H, Watanabe K: Perforation of the small intestine caused by metastasis from primary lung cancer: report of two cases and the discussion of 48 cases published in the Japanese literature. Nihon Kokyuki Gakkai Zasshi 2007, 45(5):430-5.

14. Kim SY, Ha HK, Park SW, Kang J, Kang J, Kim KW, Lee SS, Park SH, Kim AY Gastrointestinal metastasis from primary lung cancer: $\mathrm{CT}$ findings and clinicopathologic features. AJR Am J Roentgenol 2009, 193:W197-201.

15. Scagliotti GV, Parikh P, von Pawel J, Biesma B, Vansteenkiste J, Manegold C, Serwatowski P, Gatzemeier U, Digumarti R, Zukin M, Lee JS, Mellemgaard A, Park K, Patil S, Rolski J, Goksel T, de Marinis F, Simms L, Sugarman KP, Gandara D: Phase III study comparing cisplatin plus gemcitabine with cisplatin plus pemetrexed in chemotherapy-naive patients with advanced-stage non-small-cell lung cancer. J Clin Oncol 2008, 26(21):3543-51.

16. Hirai S, Hamanaka Y, Mitsui N, Sato K, Chatani N: Solitary metachnonous jejunum and duodenum metastasis after surgical resection of lung cancer. Kyobu Geka 2010, 63(2):129-32.

17. Muro M, Yoshioka T, Idani H, Ishikawa T, Ishii T, Asami S, kubo S, Kurose $Y$, Hirata M, Yamashita T, Kin H: Small bowel metastasis from non-small cell lung cancer. Kyobu Geka 2008, 61(9):765-7.

18. Kant KM, Noordhoek Hegt V, Aerts JG: A patient with four-year survival after nonsmall cell lung carcinoma with a solitary metachronous small bowel metastasis. J Oncol 2010, 2010:616130.

\section{Submit your next manuscript to BioMed Central and take full advantage of:}

- Convenient online submission

- Thorough peer review

- No space constraints or color figure charges

- Immediate publication on acceptance

- Inclusion in PubMed, CAS, Scopus and Google Scholar

- Research which is freely available for redistribution

Submit your manuscript at www.biomedcentral.com/submit 